Article

\title{
Sound Absorption Characterization of Natural Materials and Sandwich Structure Composites
}

\author{
Jichun Zhang ${ }^{1}$, Yiou Shen ${ }^{1, *}$ (D), Bing Jiang ${ }^{1}$ and Yan $\mathrm{Li}^{1,2}$ \\ 1 School of Aerospace Engineering and Applied Mechanics, Tongji University, Shanghai 200092, China; \\ zhangjichun@tongji.edu.cn (J.Z.); 18686380740@163.com (B.J.); liyan@tongji.edu.cn (Y.L.) \\ 2 Key Laboratory of Advanced Civil Engineering Materials, Ministry of Education, Tongji University, \\ Shanghai 200092, China \\ * Correspondence: shenyiou@tongji.edu.cn; Tel.: +86-21-6598-5919
}

Received: 19 June 2018; Accepted: 5 July 2018; Published: 11 July 2018

\begin{abstract}
Natural fiber and wood are environmentally friendly materials with multiscale microstructures. The sound absorption performance of flax fiber and its reinforced composite, as well as balsa wood, were evaluated using the two-microphone transfer function technique with an impedance tube system. The microstructures of natural materials were studied through scanning electrical microscope in order to reveal their complex acoustical dissipation mechanisms. The sound absorption coefficients of flax fiber fabric were predicted using a double-porosity model, which showed relatively accurate results. The integrated natural materials sandwich structure was found to provide a superior sound absorption performance compared to the synthetic-materials-based sandwich structure composite due to the contribution of their multiscale structures to sound wave attenuation and energy dissipation. It was concluded that the natural-materials-based sandwich structure has the potential of being used as a sound absorption structure, especially at high frequency.
\end{abstract}

Keywords: plant fiber; balsa; sound absorption; microstructures; sandwich structures

\section{Introduction}

Over the last couple of decades, there has been an increasing demand for improving the interior noise and indoor noise of aircraft, railway, automobile, and building compartments. Interior noise impairs people's health and causes a decrease in passenger comfort and active safety performance [1]. The use of sound-absorbing materials is one of the present effective noise control technologies. The conventional industrial sound absorption and insulation materials are mineral fibers, foam, and their composites. However, the usage of such materials is expensive, energy-consumptive, and adds more weight to the structures, which impacts their structural integrity.

Sandwich structure composites have been extensively employed in aerospace, transportation, construction, and new energy fields as load-bearing components due to their high strength-to-weight ratio. Sandwich structure composites can be designable and multifunctional, and more functions can be provided besides bearing with proper design, such as impact tolerance, thermal isolation, radiation resistance, acoustic absorption, etc. Nowadays, growing attention has focused on environmentally friendly materials that can be recycled or need less energy for production and contribute minimum greenhouse gas emissions. Utilizing natural materials as face sheets or core materials for sandwich structures would provide superior load-bearing and fatigue properties. Moreover, this kind of structure provides good sound absorption properties compared to the conventional metallic and laminated composite structural members [2]. These natural materials and sandwich structures have the potential of replacing synthetic materials in applications with demands of weight constraints or 
environmental friendliness, such as interior panels or floors in the aerospace industry, high-speed trains, and automobiles.

Zheng and $\mathrm{Li}$ [3] found using plant-fiber-reinforced composite (PFRC) as skins of sandwich structures processes better sound absorption properties than using glass-fiber-reinforced composite (GFRC) as skins. The damping properties of flax-fiber-reinforced composite (FFRC) face sheets and GFRC face-sheet-based sandwich structures were compared by Petrone et al. [4,5]. Their research results indicated that FFRC face sheet sandwich panels have outperformed energy dissipation ability compared to the synthetic fiber face sheet ones. Sarginis et al. [6] investigated the sound and vibration damping characteristics of balsa-core-based sandwich beams. They found that the coincidence frequency of sandwich beams with natural fiber facing sheet and balsa core was tripled compared to a synthetic-core-based sandwich beam. Plant fiber is a kind of natural material, and it has been widely used as reinforcement in composite structures for the last decades due to their rich source, low price, specific strength, high specific modulus, and so on. Plant fiber has a complex, multiscale, hollow structure compared with synthetic fiber $[7,8]$. For example, flax fiber is extracted from the stalk of the plant, and the characteristics of its natural growth result in its multiscale structure, which can be simplified at two scales. At the mesoscopic scale, a bundle contains 10 to 40 elementary fibers (12-16 $\mu \mathrm{m}$ in diameter, $2-5 \mathrm{~cm}$ in length) which are linked together mainly by pectin. At the microscopic scale, different from the solid structure of synthetic fiber, each elementary fiber is made up of concentric cell walls called the primary cell wall $(0.2 \mu \mathrm{m})$ and the secondary cell wall. The secondary cell wall is composed of three layers, namely the S1 layer $(0.08-0.2 \mu \mathrm{m})$, the S2 layer $(1-10 \mu \mathrm{m})$, and the S3 layer $(0.1 \mu \mathrm{m})$. Most of the cellulose microfibrils are located in the S2 layer, which is a type of polymer and possesses viscoelastic properties. The S2 layer of flax fiber consists of numerous cellulose microfibril sublayers $\left(L_{1}, L_{2} \ldots L_{n}\right)$ which run parallel to each other and form a microfibril angle with the fiber direction. At the center of the elementary fiber, there is a $2-5-\mu \mathrm{m}$ diameter small open channel called lumen, as revealed in Figure 1a. It can be seen from Figure $1 \mathrm{~b}$ that hundreds of elementary fibers twist together to form a continuous yarn, and a gap of dozens of microns is between each elementary fiber. The unique microstructure brings many distinctive advantages for plant fiber, such as superior energy absorption [9], acoustic [10] and damping [11] performances, etc. Natural fiber was found to be a good acoustically absorbent material due to the hollow structures which efficiently convert acoustic energy into mechanical and heat energy [12]. The investigations on the acoustic absorption properties of natural-fibrous-material-reinforced composites are limited; however, several scholars have experimentally studied the sound absorption coefficients of plant-fiber-reinforced composites (PFRC) and found their sound absorption coefficients (SAC) were much higher than those of the synthetic-fiber-reinforced composites at 100-2000 Hz frequency level [12,13]. Yang and Li [14] also found that the Garai-Pompoli model and Delany-Bazley model have good agreement with the experimental results. However, the acoustical dissipation mechanisms of plant fiber materials were not plenarily analyzed in these studies and the multiscale hollow structure of plant fibers was not reflected by these two models. Therefore, the multiscale structure of plant fiber should be considered during sound absorption mechanisms analysis as well as the acoustic properties prediction. Olny and Boutin [15] theoretically studied the acoustic wave propagation in media with two interconnected networks of pores of very different characteristic sizes. In this study, flax fiber yarn was considered as a double-porosity media, and this double-porosity model was employed to predict the acoustic properties of flax fiber.

The relatively high mechanical properties and low density of balsa make it attractive for cores in sandwich panels, and more importantly, sustainable. To date, there are no engineered materials suitable for sandwich panel cores with a similar combination of mechanical properties and low density [16]. Balsa wood can be considered as a kind of cellular material; it is composed of different size cell fibers, rays, and vessels, and there are also many micropores connecting each grain. It can be seen from Figure $2 \mathrm{a}, \mathrm{b}$ that the fibers are long prismatic cells, resembling a hexagon in cross-section, ranging from 20 to $40 \mu \mathrm{m}$ in diameter. The rays are brick-like parenchyma cells ranging from 20 to $40 \mu \mathrm{m}$ 
in cross-section. The vessels are long, tubular structures that run axially along the trunk of the tree, and the diameter of the vessels is $200-350 \mu \mathrm{m}$. Tiny micropores with a diameter of a few microns generally exist on the cell wall as seen in Figure 2c, which make it a kind of semi-open cellular structure. The thickness of the double cell wall is about 0.8 to $3 \mu \mathrm{m}$ in fibers as shown in Figure $2 \mathrm{~d}$. Balsa wood also possesses a multiscale structure, and the cell wall is similar to that of natural fiber, which consists of a primary layer and three secondary layers, the S1, S2, and S3, and the S2 layer is generally the thickest layer [17]. The cell wall of wood is a composite structure in which cellulose microfibrils are reinforced with hemicelluloses and lignin. Therefore, this structure lowers the density and has a competitive mechanical performance with commercial close-cell foam. Many researchers have investigated the mechanical performance of balsa $[18,19]$ and balsa-based sandwich structures $[20,21]$, and they found the balsa core sandwiches were stiffer than traditional polymer-based sandwiches and have better energy absorption capacity. Only a few researchers have focused on the acoustic absorption properties of this natural cellular-material-based sandwich structure, and they believed that balsa, with a high volume of pores, also has great potential as noise absorption material [6].
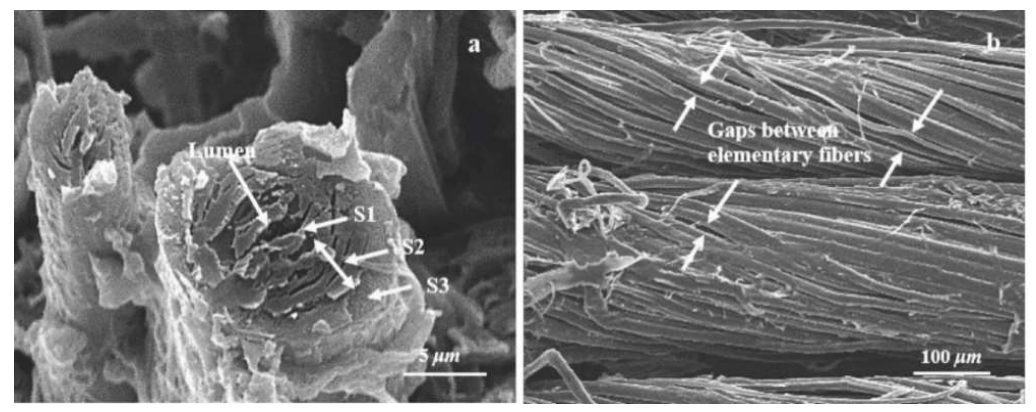

Figure 1. (a) Cross-section of an elementary flax fiber and (b) flax fiber yarns.
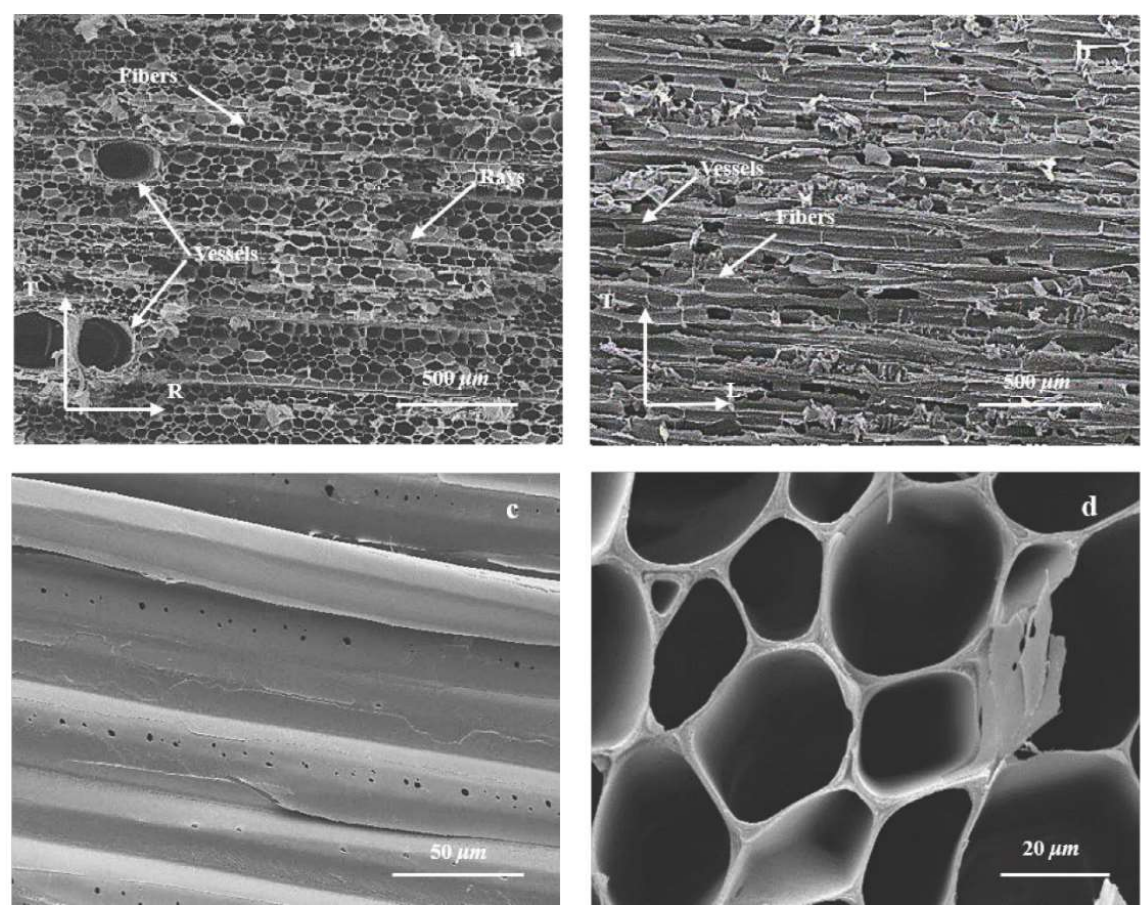

Figure 2. SEM micrographs of balsa wood (a) cross-section; (b) longitudinal view; (c) micropores on fibers; and (d) multilayer cell wall. L, R, and T refer to the longitudinal, radial, and tangential axes of symmetry. 
Considering the complicated multiscale structure of natural materials, different acoustic absorption mechanisms may be found for the natural materials and their composite structures compared to the synthetic fiber and reinforced composites. However, the above studies have not focused on this point, thus the sound absorption mechanism of natural materials and its composite structures is still unclear. In this paper, the sound absorption performance of flax fiber, reinforced composite, balsa wood, and the integrated sandwich structure composites were evaluated using the impedance tube method. The acoustical dissipation mechanisms were analyzed on the point of view of their unique multiscale microstructures. With a purpose of comparison, commonly used sandwich composites with glass fiber face sheets and polyethylene terephthalate (PET) foam core were also investigated.

\section{Materials and Experiments}

\subsection{Materials}

Flax-fiber-fabric-reinforced epoxy composite was used as skins and balsa wood was used as the core material for Flax-Balsa sandwich structures. Likewise, Flax-PET and Glass-PET sandwich structures were prepared for comparison. The unidirectional flax fabric was provided by Lineo Co. Ltd., Saint Martin Du Tilleul, France, and the unidirectional glass fabric was provided by Zhejiang Mengtai Reinforced Composite Material Co. Ltd., Jiaxing, China. These two fabrics had similar areal density, however, the thickness of the glass fiber fabric was only half of the flax fiber fabric due to the density reason. The NPEL-128 epoxy was supplied by Shanghai Zhongsi Industry Co. Ltd., Shanghai, China. The balsa wood and the AIREX ${ }^{\circledR}$ T92.100 close-cell PET foam were supplied by Zhuhai Dechi Technology Co. Ltd., Zhuhai, China and 3A Composites (China) Ltd., Shanghai, China, respectively. The detail parameters of the flax and glass fiber fabric used for fabricating the sandwich structure skins are listed in Table 1.

Balsa wood and PET foam panel with a thickness of $10 \mathrm{~mm}$ were prepared as core materials to fabricate the sandwich structure. The basic parameters of these two types of core material are shown in Table 2. Balsa wood and PET foam with similar density and porosity were selected in this study for comparison.

Table 1. The details of fiber fabrics used in manufacturing sandwich structures skins.

\begin{tabular}{|c|c|c|c|c|c|c|c|}
\hline Materials & $\begin{array}{l}\text { Fiber Density } \\
\left(\mathrm{g} / \mathrm{cm}^{3}\right)\end{array}$ & $\begin{array}{c}\text { Mean Fiber } \\
\text { Diameter }(\mu \mathrm{m})\end{array}$ & $\begin{array}{c}\text { Mean Yarn } \\
\text { Diameter }(\mu \mathrm{m})\end{array}$ & $\begin{array}{c}\text { Areal } \\
\text { Density }\left(\mathrm{g} / \mathrm{m}^{2}\right)\end{array}$ & $\begin{array}{c}\text { Mean } \\
\text { Thickness (mm) }\end{array}$ & $\begin{array}{c}\text { Specific } \\
\text { Strength } \\
\left(\mathrm{MPa} / \mathrm{g} / \mathrm{cm}^{3}\right)\end{array}$ & $\begin{array}{c}\text { Specific } \\
\text { Modulus } \\
\left(\mathrm{GPa} / \mathrm{g} / \mathrm{cm}^{3}\right)\end{array}$ \\
\hline Flax fabric & 1.5 & 15 & 200 & 213.3 & 0.2 & 1034 & 55 \\
\hline Glass fabric & 2.55 & 11 & 100 & 207.5 & 0.1 & 980 & 30 \\
\hline
\end{tabular}

Table 2. The parameters of core materials used in manufacturing sandwich structures.

\begin{tabular}{cccccc}
\hline Materials & $\begin{array}{c}\text { Density } \\
\left(\mathbf{k g} / \mathbf{m}^{\mathbf{3}}\right)\end{array}$ & Porosity & $\begin{array}{c}\text { Cellular } \\
\text { Diameter }(\boldsymbol{\mu m})\end{array}$ & $\begin{array}{c}\text { Axial Compression } \\
\text { Modulus (MPa) }\end{array}$ & $\begin{array}{c}\text { Transverse Compression } \\
\text { Modulus (MPa) }\end{array}$ \\
\hline $\begin{array}{c}\text { Balsa wood } \\
\text { PET foam }\end{array}$ & 125 & 0.920 & $35-200$ & $280-320$ & $30-80$ \\
\hline
\end{tabular}

\subsection{Fabrication}

The epoxy resin, curing agent, and accelerating agent were mixed at the weight ratio of 100:80:1. Initially, 12 layers of flax fiber fabrics and 24 layers of glass fiber fabrics were impregnated with the resin system and laid inside of a steel mold in stacking sequence of $[0 / 90 / 0]_{2 s}$ and $\left[0_{2} / 90_{2} / 0_{2}\right]_{2 s}$, respectively. In addition, 6 layers of impregnated flax fiber fabrics were laid on the top and bottom of the core material with stacking sequence of $[0 / 90 / 0]_{s}$ in order to fabricate flax-fiber-reinforced composite (FFRC) skin-based sandwich panels. A similar process was used for GFRP skin-based sandwich panels (12 layers on each side, $\left[0_{2} / 90_{2} / 0_{2}\right]_{s}$ ). The resulting laminates and sandwich prepreg 
systems were then respectively placed in a hot press machine under pressure of $1 \mathrm{MPa}$ and temperature of $120^{\circ} \mathrm{C}$ for $2 \mathrm{~h}$ for complete curing. Two types of composite laminate, being flax-fiber-reinforced composite (FFRC) and glass-fiber-reinforced composite (GFRC), with mean thickness of $4 \mathrm{~mm}$ and fiber volume fraction of 50\% were manufactured. Three types of sandwich structures, Flax-Balsa, Flax-PET, and Glass-PET, with $2 \mathrm{~mm}$ thickness and 50\% fiber volume fraction of composite skin on each side were manufactured, in which Flax-Balsa and Flax-PET denote sandwich structures based on FFRC skins and balsa or PET foam cores, respectively. The thickness of the balsa panel was on the tangential direction of the balsa wood. The Glass-PET denotes a sandwich structure with GFRC skins and PET foam core, as illustrated in Figure 3.
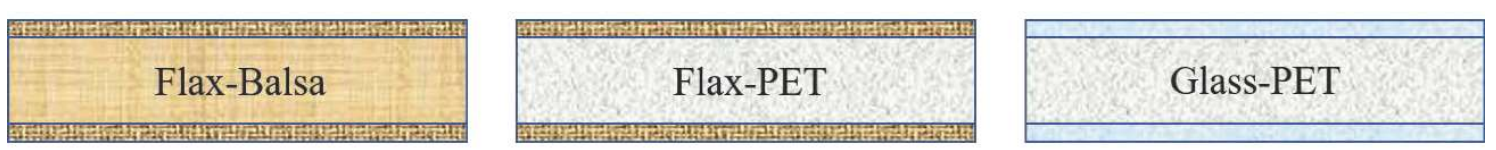

Figure 3. Schematic diagram of sandwich structures.

\subsection{Acoustic Property Measurement}

Sound absorption measurement was performed using the impedance tube method. The sound absorption coefficient (SAC) of sandwich composites was measured through a transfer function technique with the impedance tube facilities manufactured by BSWA Technology Co. Ltd., Beijing, China. The SAC is defined as the ratio of the absorbed sound energy and the incident sound energy. The measurements were conducted according to ISO10534-2 standard at medium to high frequencies from 250 to $10,000 \mathrm{~Hz}$ at $25^{\circ} \mathrm{C}$ and $60 \%$ relative humidity, and at least three specimens were tested for each group. The measurements were composed of SW422, SW477, and SW499 impedance tubes with diameters of 100, 30, and $16 \mathrm{~mm}$ for measuring frequencies from 250-2000, 800-6300, and $2500-10,000 \mathrm{~Hz}$, respectively. Samples were backed up by a rigid wall which reflected all the incoming sound energy. Two microphones were mounted at the wall of the tube to measure the sound pressure. Therefore, if the incident sound energy was known and the transmission sound energy could be measured with the aid of the transfer function, the sound energy absorbed by the materials could be obtained, as illustrated in Figure 4.

The SACs of 12 layers of flax fiber fabric and 24 layers of glass fiber fabric with same thickness were initially measured at frequency ranging from 250 to $4000 \mathrm{~Hz}$. The composite laminates and sandwich structures were carefully cut to the required size and wrapped with Teflon tape provided by 3M Company, Maplewood, MN, USA to prevent air leaks between the sample and tube. All the samples were put in the oven at $120^{\circ} \mathrm{C}$ for $4 \mathrm{~h}$ to remove moisture.

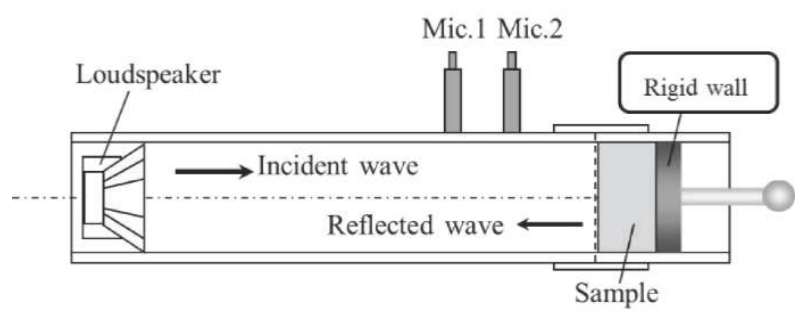

Figure 4. Instrumentation for the transfer function method of measuring sound absorption coefficients.

\section{Results and Discussions}

\subsection{Sound Absorption Performance of Flax Fiber and Its Reinforced Composite}

The tested sound absorption coefficients of unidirectional flax fiber fabric and glass fiber fabric are presented in Figure 5 as a function of frequency. The results show that in the test frequency range 
of $250-4000 \mathrm{~Hz}$, flax fiber fabric has superior acoustic absorption ability compared to glass fiber fabric. It can be seen from Figure 5 that the SACs of flax fiber fabric were higher than 0.5 when the sound wave frequency was over $1000 \mathrm{~Hz}$, which means over half of the incident sound energy was absorbed by the fabric. In this study, the critical frequency of flax fiber fabric was $3200 \mathrm{~Hz}$, which means the SAC reached a peak value of 0.96 at $3200 \mathrm{~Hz}$ and showed a relatively stable sound absorption ability afterwards. Clearly, the maximum SAC of glass is much lower than that of the flax fiber, only 0.58 in the test frequency range, and the critical frequency is higher than that of the flax fiber $(>4000 \mathrm{~Hz})$. This means flax fibers process not only outstanding sound absorption capability but also wider sound absorbing frequency range.

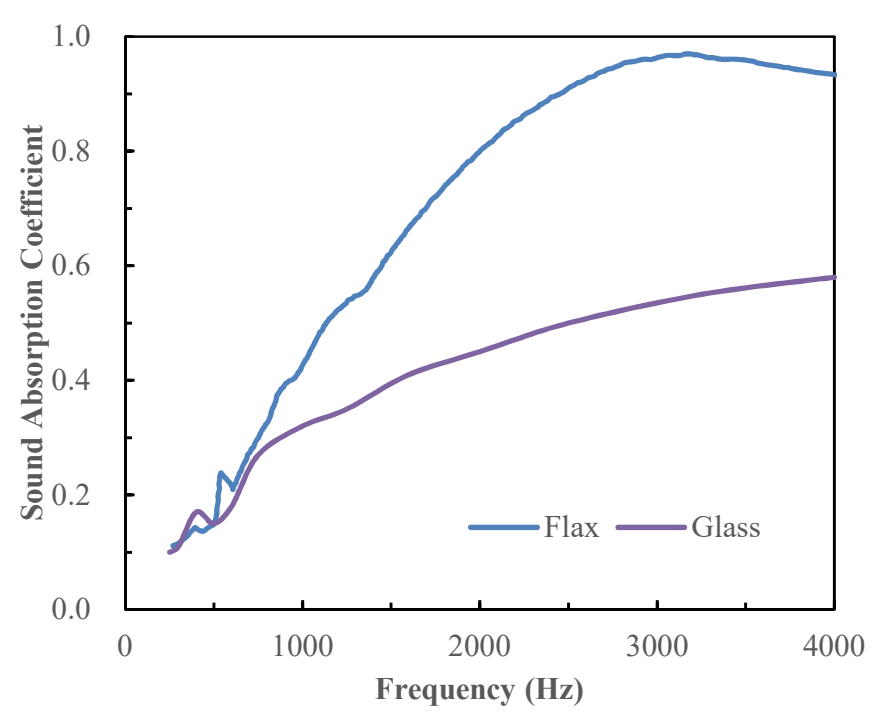

Figure 5. The experimental sound absorption coefficients of unidirectional flax and glass fiber fabrics with frequency.

It is well known that the mechanism of sound attenuation for fibrous materials is due to the interaction between acoustic waves and fiber assemblies, and the resonant frequency of sound wave absorption could be mainly attributed to the vibration of fibrous materials [12]. For natural fibrous material, the acoustic absorption mechanism is more complicated compared to the synthetic fibrous material due to its complex microstructure. As the mechanism illustrated in Figure 6 shows, the hollow and multiscale structure of flax fiber acts on the reduction and dissipation of sound energy in several manners. Firstly, the incident sound wave arouses the vibration of air molecules between elementary fibers and within the lumens, which causes interaction between air and the fiber cell wall. The resulting viscous resistance transfers this part of acoustic energy to thermal energy. Meanwhile, thermal exchange between neighboring particles of fiber also results in acoustic attenuation. Most importantly, differing from the solid structure of glass fiber, vibration and friction of microscale or even nanoscale microfibrils in elementary flax fiber also have an effect on the extra dissipation of sound energy besides vibration and friction between elementary fibers, leading to a more efficient conversion from sound energy to thermal energy. It can be seen from Figure 1a that there existed a large number of gaps between adjacent $\mathrm{S} 2$ sublayers in some regions. In this case, interfacial friction between adjacent sublayers may also dissipate energy. Moreover, the large fiber yarn diameter of flax fiber fabric causes bigger interspace between adjacent fibers, which leads to the better mobility of air in fabric and smaller surface impedance of the composite. Therefore, the sound wave can easily transmit into the flax fiber fabric and be absorbed or dissipated, consequently enhancing the sound absorption of the materials. This explains the high sound absorption coefficients of flax fiber in Figure 5. 


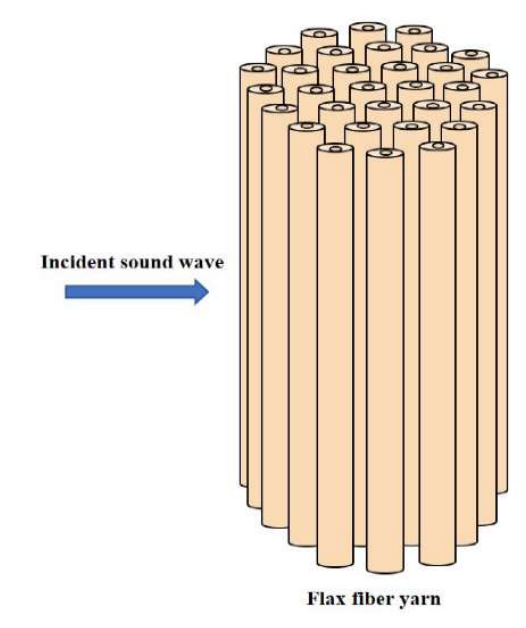

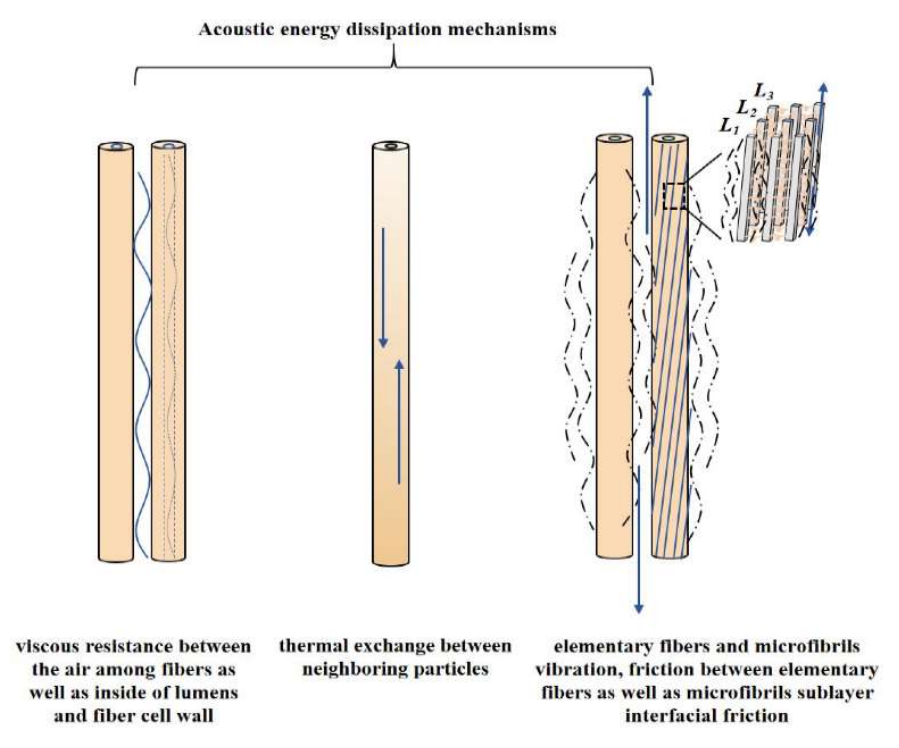

Figure 6. Acoustic energy dissipation mechanisms of flax fiber yarns.

The superior sound absorbing ability of plant fiber is essentially attributed to its multiscale micromorphology. However, the multiscale hollow structure of plant fibers was not reflected by the Garai-Pompoli model or Champoux-Allard model in predicting the SACs of plant fibers. In this study, the lumen of flax fiber was considered in predicting its acoustic properties. Firstly, an idealized flax elementary fiber was assumed as a $15-\mu \mathrm{m}$ diameter tubular cell with a $5-\mu \mathrm{m}$ diameter lumen inside. The effective density $\rho_{e q}$ and the effective modulus $K_{e q}$ of unidirectional flax fiber fabric were predicted according to the double-porosity model developed by Olny and Boutin [15] as shown in Equations (1) and (2):

$$
\begin{gathered}
\rho_{e q}(\omega)=\left(\frac{1}{\rho_{p}(\omega)}+\frac{1-\varnothing_{p}}{\rho_{m}(\omega)}\right)^{-1} \\
K_{e q}(\omega)=\left(\frac{1}{K_{p}(\omega)}+\frac{\left(1-\varnothing_{p}\right) F_{d}\left(\omega, \omega_{d}\right)}{K_{m}(\omega)}\right)^{-1}, \omega_{d} \approx \frac{P_{0}}{\varnothing_{m} \sigma_{m} l_{p}^{2}}
\end{gathered}
$$

where subscripts ' $p$ ' and ' $m$ ' present the mesoscopic scale (between fibers) and microscopic scale (within the fiber). $l_{p}$ and $l_{m}$ present the characteristic length in these two scales. $\rho_{p}(\omega), \rho_{m}(\omega)$, and $K_{p}(\omega)$ were obtained by plugging the basic mesoscopic and microscopic scales acoustic parameters into the Champoux-Allard model, Equations (3) and (4). $F_{d}$ is a pressure diffusion function. In this study, the test frequency $\omega<\omega_{d}, F_{d} \approx 1$ and voids at both scales participated in the attenuation of acoustic energy; the sound pressure between fibers and lumens are the same.

$$
\begin{gathered}
\rho_{e q}(\omega)=\frac{\rho_{0} \alpha_{\infty}}{\varnothing}\left\lfloor 1-i \frac{\sigma \varnothing}{\omega \rho_{0} \alpha_{\infty}} \sqrt{1+i \omega \rho_{0} \eta\left(\frac{2 \alpha_{\infty}}{\sigma \varnothing \Lambda}\right)^{2}}\right] \\
\frac{1}{K_{e q}}(\omega)=\frac{\varnothing}{\gamma P_{0}}\left\{\gamma-(\gamma-1)\left[1-i \frac{8 \eta}{\omega \rho_{0} P_{r} \Lambda^{\prime 2}} \sqrt{1+\frac{i \omega \rho_{0} P_{r}}{\eta}\left(\frac{\Lambda^{\prime}}{4}\right)^{2}}\right]^{-1}\right\}
\end{gathered}
$$

where $\omega$ is the angular frequency, $\omega=2 \pi f, f$ is the incident sound wave frequency, $\varnothing$ is the porosity, and $\alpha_{\infty}$ is the tortuosity, which characterizes the buckling of channels in the material. For ideal fiber materials, $\alpha_{\infty}=1.34 . \Lambda$ and $\Lambda^{\prime}$ are viscous characteristic length and thermal characteristic dimension, which characterize the average diameter of unit length for viscous loss and thermal loss, respectively. $\Lambda$ and $\Lambda^{\prime}$ are defined as $\Lambda=1 / 2 \pi r L, \Lambda^{\prime}=2 \Lambda$, in which $L=4 \rho f / \pi a^{2} \rho_{b}, r=a / 2, a$ is fiber diameter and 
$\rho_{b}$ is the fabric density. $\rho_{0}$ and $\gamma$ are air density and specific heat ratio, respectively, and $P_{0}$ is the atmospheric pressure. $P r$ is the Prandtl number, defined as $P_{r}=C_{p} / k$, where $C_{p}$ is isobaric heat capacity, $\mu$ is viscosity, and $k$ is thermal conductivity. The Prandtl number characterizes the effect of the physical characteristic of air on the heat transfer process. The porosity can be obtained by Equation (5)

$$
\varnothing=1-\frac{\rho_{b}}{\rho_{f}}
$$

where $\rho_{f}$ is the fiber density.

The resulting $\rho_{e q}$ and $K_{e q}$ were then substituted into Equation (6) to get the acoustic characteristic impedance, $Z_{e q}$, and wave number, $k_{e q}$, of flax fiber fabric. The sound absorption coefficients can then be obtained using Equation (9)

$$
\begin{gathered}
Z_{e q}=\sqrt{\rho_{e q} K_{e q}}, \quad k_{e q}=\omega \sqrt{\frac{\rho_{e q}}{K_{e q}}} \\
\alpha=1-\left|\frac{Z_{n}-1}{Z_{n}+1}\right|^{2}, Z_{n}=-i \frac{Z_{e q}}{\rho_{0} c_{0}} \operatorname{coth}\left(k_{e q} t\right)
\end{gathered}
$$

where $c_{0}$ is the sound velocity in air, $t$ is the thickness of material. It can be observed from Equations (3)-(7) that the acoustic parameters of material are related to its physical parameters, including fiber diameter, fiber density, fabric density, and fabric thickness. It indicates that these physical parameters of material play a critical role on the sound absorption properties.

It can be found from Figure 7 that the double-porosity model showed more accuracy predicting results compared to the Champoux-Allard model [22], and the critical frequency of flax fiber fabric was accurately estimated. This indicates that the main factors affecting the sound absorption properties of plant fiber materials are not only fiber diameter, density, and fabric density, but the lumen diameter is also an important parameter. The double-porosity model can be used to predict the sound absorption coefficients of plant fibers effectively.

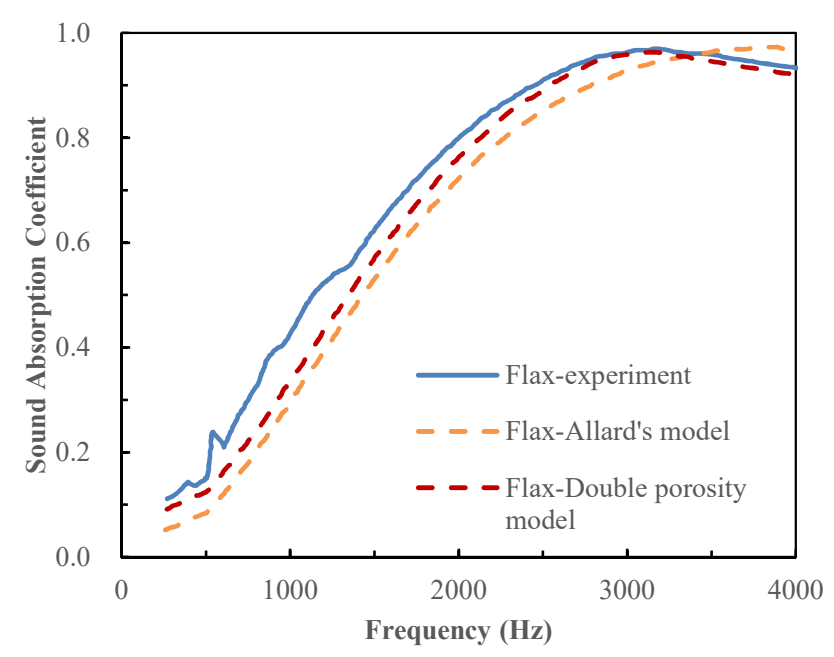

Figure 7. Comparison of experimental and theoretical sound absorption coefficients of unidirectional flax fiber fabrics with frequency.

Figure 8 compares the experimental results on SACs of flax fiber and glass-fiber-reinforced composites. FFRC laminate provides superior sound absorption capacity to GFRC especially at higher frequency, as expected. However, the SACs of the composites are obviously much lower than the fiber fabric and the effective sound absorption frequency range (SACs value over 0.2) was reduced. This is due to the reason that when an incident sound wave reaches the surface of material, partial sound 
energy is reflected. The reflected energy depends on the surface acoustic impedance, $Z$, which can be described using Equation (8).

$$
Z=\sqrt{E \cdot \rho}
$$

where $E$ is the modulus of the materials (sound wave incident direction) and $\rho$ is the density of the materials. The sound wave can be easily reflected when $Z$ is high and more sound energy is reflected. In contrast, a substantial part of sound energy enters into the materials when $Z$ is low. Apparently, more sound energy was reflected by the composite and this limited its sound absorption ability. Furthermore, the microstructure of the material structure had a major effect on energy dissipation at high frequency due to the very short wavelength of sound wave, which made it easily eliminated when transmitted through the media. The SACs of pure epoxy are very low, generally below 0.2 . Thus, the sound absorption performance of composite laminate is mainly dependent on the sound absorption characteristics of fiber. Previous work [23] has found that the multilayer structure of flax fiber provided more internal interfaces (primary cell wall, S1, S2, and S3 layers of the secondary cell wall, and S2 layer consist of numerous cellulose microfibril sublayers) and paths inside of flax fiber to dissipate energy compare to the solid synthetic fiber. Therefore, the damping property of flax fibers was much better and resulted in a higher damping ratio for its reinforced composite. This indicates that the FFPC possesses higher energy dissipation and acoustic-thermal conversion capacity, and it also evidences its better acoustic absorption performance than that of GFRP. Prabhakaran et al. [13] also found FFRC process better SACs and damping factors compared to GFRC.

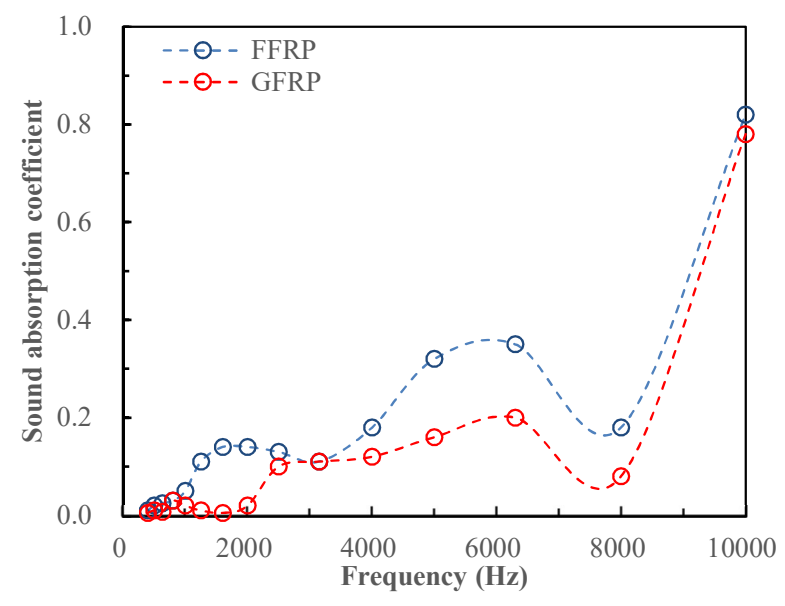

Figure 8. The experimental sound absorption coefficients of FFRC and GFRC with frequency.

\subsection{Sound Absorption Performance of Balsa Wood}

Figure 9 illustrates the SACs of balsa and PET foam, which indicate that these two types of core materials possess similar sound absorption ability along the test frequencies. The peak value of SACs below $10,000 \mathrm{~Hz}$ for these two materials are 0.4 and 0.42 , respectively. The maximum SAC of these two porous materials at $10,000 \mathrm{~Hz}$ are also very close, being 0.85 and 0.87 . The similar density and porosity of these two materials lead to their essentially identical trend on the sound absorption behavior. The cell wall of balsa is composed of polymer materials, and the visco-inertial and thermal damping dominates the sound absorption behavior for polymeric foams. In low frequency stage, thermal exchange is dominated in energy dissipation, whereas in high frequency, viscous resistance is the main energy consuming method. The loss of sound energy is mainly due to the contribution of the porous sound absorption mechanism and resonance absorption mechanism. The air molecules periodically vibrate under the influence of sound waves; meanwhile, the friction between the air molecules and cell wall cause frictional heat. On the other hand, the compression and expanding deformation of air inside of the cell occurs; this transfers partial sound energy into thermal energy. In terms of balsa, vibration 
and friction of cellulose microfibrils in the cell wall and interfacial friction between adjacent sublayers caused sound energy dissipation, which is similar to the flax fiber. In addition, the micropores in the cell wall of balsa consumed sound energy due to this complex inner geometry providing a tortuous sound path through the foam. It can be found that natural material has a complicated acoustical energy dissipation mechanism due to its natural growth multiscale structure which reveals a satisfactory sound absorption performance.

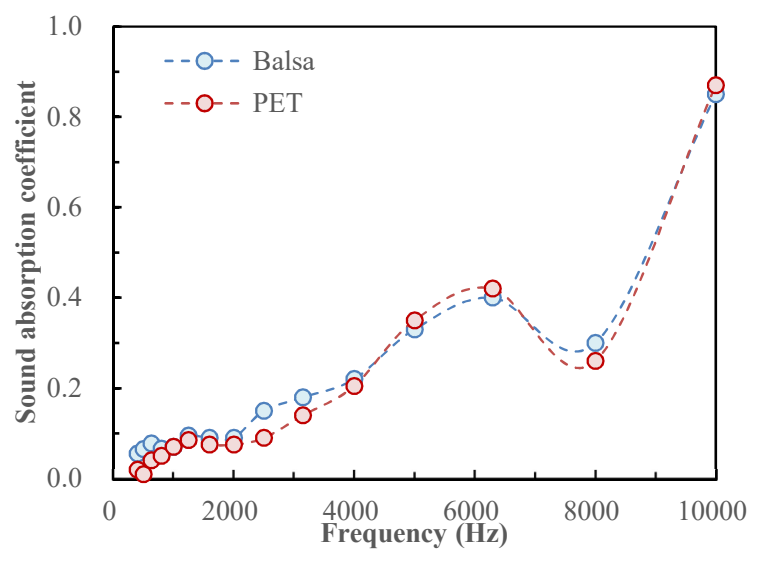

Figure 9. The experimental sound absorption coefficients of balsa and PET foam with frequency.

\subsection{Sound Absorption Performance of Sandwich Structures}

An effective way to improve the acoustic absorption performance of composite laminate is inducing a porous material as the core material to cooperate a sandwich structure. Meanwhile, the sound wave can be reflected repeatedly by the stiff composite skins back to the interior of the cellular core material for energy exchange and dissipation. Figure 10 shows the variation of SACs with frequency of Flax-Balsa, Flax-PET, and Glass-PET sandwich structures and their corresponding core materials. It can be seen from Figure 10 that the SACs increase with frequency for all the samples, reaching at least 0.8 at 10,000 Hz. For flax-fiber-reinforced composite skin-based sandwich structures, the SACs of the sandwich panel are higher than those of the core materials in all frequency levels. The SACs are clearly improved for the balsa if cooperated with FFRC skins from $1600 \mathrm{~Hz}$. The sound absorption peak of the Flax-Balsa sandwich panel is 0.65 , which is approximately $63 \%$ and $86 \%$ enhancement compared to that of the balsa and FFRC, respectively. On the other hand, the SACs of PET foam have been distinctly enhanced over $40 \%$ at high frequency from $4000 \mathrm{~Hz}$ when cooperated with FFRC skins. It can be concluded that flax fiber skin-based sandwich structures provide better sound absorption performance than their corresponding core materials at a large range of frequency band, and the composite skins definitely play a significant role. The dashed line represents the effective sound absorption peak width (SACs value over 0.2) which has been enlarged from $4000-8000 \mathrm{~Hz}$ (balsa) to $3150-8000 \mathrm{~Hz}$ (Flax-Balsa). Nevertheless, the SACs of the sandwich structure with flax-fiber-reinforced skins are overall higher compared to the sandwich structures with glass fiber skins, especially at higher frequency due to the high surface acoustic impedance and low sound absorption ability of GFRC skins. Thus, choosing the appropriate fiber type for composite skins will improve the acoustic performance of sandwich structures effectively.

It is worth noting that when cooperated with flax fiber reinforced skins, the SACs of Flax-Balsa sandwiches are clearly higher than those of Flax-PET despite their core materials possessing similar acoustic behavior with the same skins. This is due to the fact that PET foam has larger cell size ranging from 500 to $700 \mu \mathrm{m}$, whereas the cell size of balsa ranges from 35 to $200 \mu \mathrm{m}$. The epoxy resin filled the layer of cells that contacted the skin during fabrication. After curing, the solid layer of epoxy resin in Flax-PET sandwich structures was much thicker than that of Flax-Balsa; this limited the sound wave 
entering into the core materials and resulted in its relatively lower SACs. It is clear from Figure 10 that the Flax-Balsa sandwich structure has the best sound absorption behavior over most of the frequency band compared to the other two sandwich structures and their core materials. The superior acoustic performance of this environmentally friendly sandwich structure plays a great role in their unique multiscale microstructure advantages.

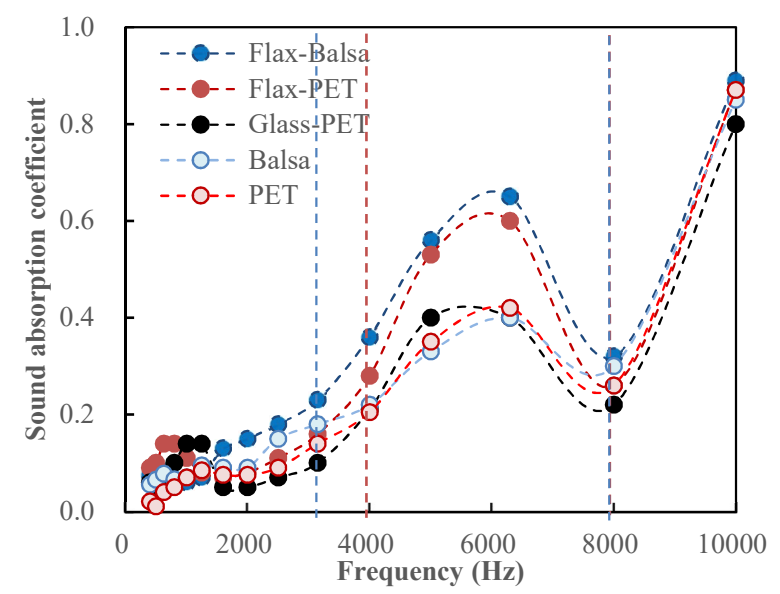

Figure 10. The experimental sound absorption coefficients of sandwich structures and their corresponding core materials.

Figure 11 illustrates the sound absorption mechanism of natural-material-based sandwich structure composites. When sound energy $\left(E_{i}\right)$ vertically incidents from one side of the structure, partial sound energy is reflected $\left(E_{r}\right)$ by the surface of the composite skin. The incident sound energy is initially absorbed $\left(E_{a 1}\right)$ by the FFRC skin through viscous resistance, thermal exchange, and damping of fibers or microfibrils and multilayer cell walls. Partial energy transmits through top skin $\left(E_{t 1}\right)$ and some energy reflects by the interface of skin and core $\left(E_{r 1}\right)$. Balsa core absorbs sound energy $\left(E_{a 2}\right)$ mainly through visco-inertial and thermal damping, multilayer cell wall damping, and air flow through micropores also causing sound energy dissipation. The residual sound energy was reflected $\left(E_{r 2}\right)$, absorbed $\left(E_{a 3}\right)$, and transmitted by the bottom skin $\left(E_{t 1}\right)$.

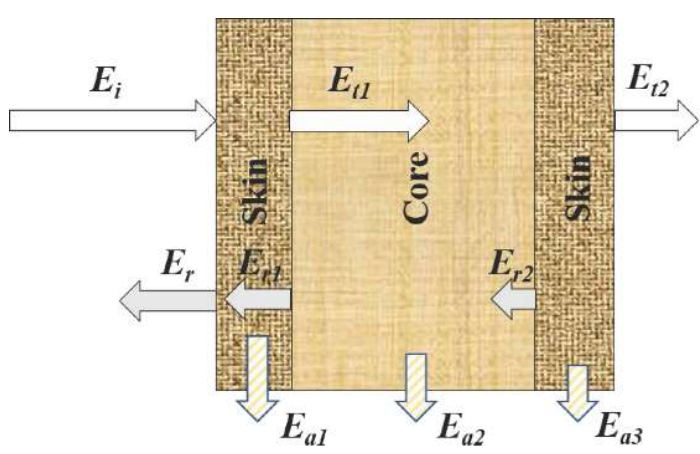

Figure 11. Schematic diagram of sound energy absorption mechanism for sandwich structure.

\section{Conclusions}

Sound absorption properties of natural materials and their integrated sandwich structure were characterized and compared with synthetic materials. It was found that the multiscale structure of natural materials was the reason for their outstanding sound energy absorption performance and complicated energy dissipation mechanism. The double-porosity model was applied for predicting the sound absorption coefficients of plant fiber yarns and it showed more accurate results compared to the 
Champoux-Allard model. This suggested that the unique multiscaled hollow structure has an effect on the acoustic behavior of plant fiber. The multilayer sandwich structure is conducive to effective and gradual dissipation of sound energy compared to the individual core material or composite laminates, especially at high frequency. With proper design, the natural-materials-based sandwich structure has the potential for being utilized as a load-bearing and sound-absorbing multifunctional structure, especially at high frequency, which would be very beneficial for aeronautical applications due to weight restriction and the high sound frequency service environment in order to increase the comfort of the passengers.

Author Contributions: Y.S. and Y.L. conceived and guided the project and study; J.Z. was responsible for the manufacturing of the sandwich structures and preparing samples; J.Z. and B.J. processed the experimental data and performed the calculation; J.Z. prepared the writing-original draft and Y.S. made the writing-review \& editing.

Funding: This paper was supported by National Natural Science Foundation (11302151) and the Fundamental Research Funds for the Central Universities.

Acknowledgments: The authors are thankful to Lineo Co. Ltd. (Saint Martin Du Tilleul, France) and BSWA Technology Co. Ltd. (Beijing, China) for supplying the natural flax fibers and the impedance tube facilities for measuring SACs respectively.

Conflicts of Interest: The authors declare no conflict of interest.

\section{References}

1. Wilby, J.F. Aircraft interior noise. J. Sound Vib. 1996, 190, 545-564. [CrossRef]

2. Liu, J.L.; Bao, W.; Shi, L.; Zuo, B.Q.; Gao, W.D. General regression neural network for prediction of sound absorption coefficients of sandwich structure nonwoven absorbers. Appl. Acoust. 2014, 76, 128-137. [CrossRef]

3. Zheng, Z.Y.; Li, Y.; Yang, W.D. Absorption properties of natural fiber-reinforced sandwich structures based on the fabric structures. J. Reinf. Plast. Compos. 2013, 32, 1561-1568. [CrossRef]

4. Petrone, G.; D'Alessandro, V.; Franco, F.; De Rosa, S. Damping evaluation on eco-friendly sandwich panels through reverberation time (RT 60) measurements. J. Vib. Control 2015, 21, 3328-3338. [CrossRef]

5. Petrone, G.; D'Alessandro, V.; Franco, F.; Mace, B.; De Rosa, S. Modal characterisation of recyclable foam sandwich panels. Compos. Struct. 2014, 113, 362-368. [CrossRef]

6. Sargianis, J.J.; Kim, H.I.; Andres, E.; Suhr, J. Sound and vibration damping characteristics in natural material based sandwich composites. Compos. Struct. 2013, 96, 538-544. [CrossRef]

7. Fratzl, P.; Weinkamer, R. Nature's hierarchical materials. Prog. Mater. Sci. 2007, 52, 1263-1334. [CrossRef]

8. Charlet, K.; Jernot, J.; Eve, S. Multi-scale morphological characterisation of flax: From the stem to the fibrils. Carbohydr. Polym. 2010, 82, 54-61. [CrossRef]

9. Meredith, J.; Ebsworth, R.; Coles, S.R.; Wood, B.M.; Kirwan, K. Natural fibre composite energy absorption structures. Compos. Sci. Technol. 2012, 72, 211-217. [CrossRef]

10. Berardi, U.; Iannace, G. Acoustic characterization of natural fibers for sound absorption application. Build. Environ. 2015, 94, 840-852. [CrossRef]

11. Duc, F.; Bourban, P.E.; Plummer, C.J.G.; Månson, J.A.E. Damping of thermoset and thermoplastic flax fibre composites. Compos. Part A-Appl. Sci. 2014, 64, 115-123. [CrossRef]

12. Tang, X.; Yan, X. Acoustic energy absorption properties of fibrous materials: A review. Compos. Part A-Appl. Sci. 2017, 101, 360-380. [CrossRef]

13. Prabhakaran, S.; Krishnaraj, V.; Senthil kumar, M.; Zitoune, R. Sound and vibration damping properties of flax fiber reinforced composites. Procedia Eng. 2014, 97, 573-581. [CrossRef]

14. Yang, W.; Li, Y. Sound absorption performance of natural fibers and their composites. Sci. China Technol. Sci. 2012, 55, 2278-2283. [CrossRef]

15. Olny, X.; Boutin, C. Acoustic wave propagation in double porosity media. J. Acoust. Soc. Am. 2003, 114, 73-89. [CrossRef] [PubMed]

16. Damian, B. An introduction to core materials. Reinf. Plast. 2014, 58, 32-37.

17. Borrega, M.; Ahvenainen, P.; Serimaa, R.; Gibson, L. Composition and structure of balsa (Ochroma pyramidale) wood. Wood Sci. Technol. 2015, 49, 403-420. [CrossRef] 
18. Borrega, M.; Gibson, L.J. Mechanics of balsa (Ochroma pyramidale) wood. Mech. Mater. 2015, 84, 75-90. [CrossRef]

19. Silva, A.D.; Kyriakides, S. Compressive response and failure of balsa wood. Int. J. Solids Struct. 2007, 44, 8685-8717. [CrossRef]

20. Atas, C.; Sevim, C. On the impact response of sandwich composites with cores of balsa wood and PVC foam. Compos. Struct. 2010, 93, 40-48. [CrossRef]

21. Osei-Antwi, M.; Castro, M.; Vassilopoulos, A.P.; Keller, T. Fracture in complex balsa cores of fiber-reinforced polymer sandwich structures. Constr. Build. Mater. 2014, 71, 194-201. [CrossRef]

22. Champoux, Y.; Allard, J. Dynamic tortuosity and bulk modulus in air-saturated porous media. J. Appl. Phys. 1991, 70, 1975-1979. [CrossRef]

23. Li, Y.; Cai, S.; Huang, X. Multi-scaled enhancement of damping property for carbon fiber reinforced composites. Compos. Sci. Technol. 2017, 143, 89-97. [CrossRef]

(C) 2018 by the authors. Licensee MDPI, Basel, Switzerland. This article is an open access article distributed under the terms and conditions of the Creative Commons Attribution (CC BY) license (http:/ / creativecommons.org/licenses/by/4.0/). 